\section{DESIGN OF DEDICATED AUTOMATED DEVICES WITH CAD SUPPORT}

\begin{abstract}
NAQIB DANESHJO ${ }^{1}$, ZUZANA HAJDUOVA ${ }^{1}$, ERIKA DUDAS PAJERSKA ${ }^{1}$, ENAYAT DANISHJOO ${ }^{2}$
\end{abstract}

${ }^{1}$ University of Economics in Bratislava, Faculty of Business Economics with seat in Kosice, Kosice, Slovak Republic ${ }^{2}$ Thk rhythm automotive GMBH, Duesseldorf, Germany

DOI : 10.17973/MMSJ.2019_03_2018128 e-mail : daneshjo47@gmail.com

The thesis deals with the problem of fixing the flexible prism element to the supporting element which is the side contact pen. The resulting component will serve for the manufacture of wall-mounted switches or work panels. The aim of this work is the main design of the mechanical construction of the device which will be able to fix the elastic element on the complicated positioning of the tongue to meet the conditions of the technological tests. The work should also specify the sequence of actions, respectively control program in block form. The machine should be designed so that it can be supplemented in the future with ancillary technological equipment that will enhance the functions and capabilities of the whole unit.

KEYWORDS

Design, CAD systems, PLM systems, complex products, fixation, structural 3D modelers, component, production

\section{INTRODUCTION}

No phase of complex product design cannot be used without computer support. Even in standard technical terminology, the CA... approach is discussing for designing and manufacturing of assemblies and their components. The administration of design offices and development centres is facing another phenomenon of human literacy with the concept of CA... the ability of a person to use sophisticated software solutions in the design of devices, with which we can design, analyse, produce individual components, respectively weld, so we can continue until its ecological disposal. It is basically about product lifecycle management during its lifetime. But we're just a step further, with PLM systems. But not so far. Slowly, CADs begin to speak as part of PLM (Product Lifecycle Management) systems [Kuderjavy 2009].

In a world full of strict criteria for safety, lifecycle, and customer pressure criteria to sell these components at the lowest price, automation is needed. This will ensure higher production efficiency, faster production, accuracy, and reduced need for trained workers' compensation. In our case, we have solved the problem of the design of a single-purpose fixation device for the finishing of the wire clamping components in the wiring elements with the help of the Pro / ENGINEER CAD (Computer Aided Design) system and in this article, we will try to briefly approach the solution, namely one operation[Stejskal 2017].

\section{OPERATION - BEND WITH FIXATION}

There is a need for mutual fixation of the two elements so that the resulting component can be used as the clamping element of the wiring of the wiring components. It is necessary to create and maintain enough contact pressure on the metal part of the conductor, in order to ensure satisfactory conditions of electric current flow, as well as avoiding dropping or pulling of the wire (this is achieved by a flexible cutting element) - see Fig. 1.

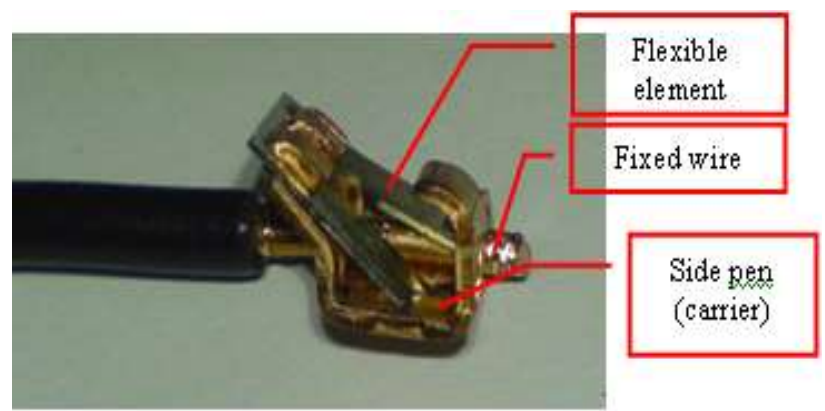

Figure 1: The way of fastened driver by the contact of the switch

After successful operations, at the input of this operation, the component is precisely positioned in the clamping device (see Fig. 3) on a rotatable work table where secure transfer of deformation forces and holding is ensured. Fig. 2 shows an overview of the succession of operations (movement of the work table). The production of matching contact is not currently taking place because it is a new type of component, but similar parts are manufactured by a manually trained operator [Daneshjo 2013] , [Kuderjavy 2010].

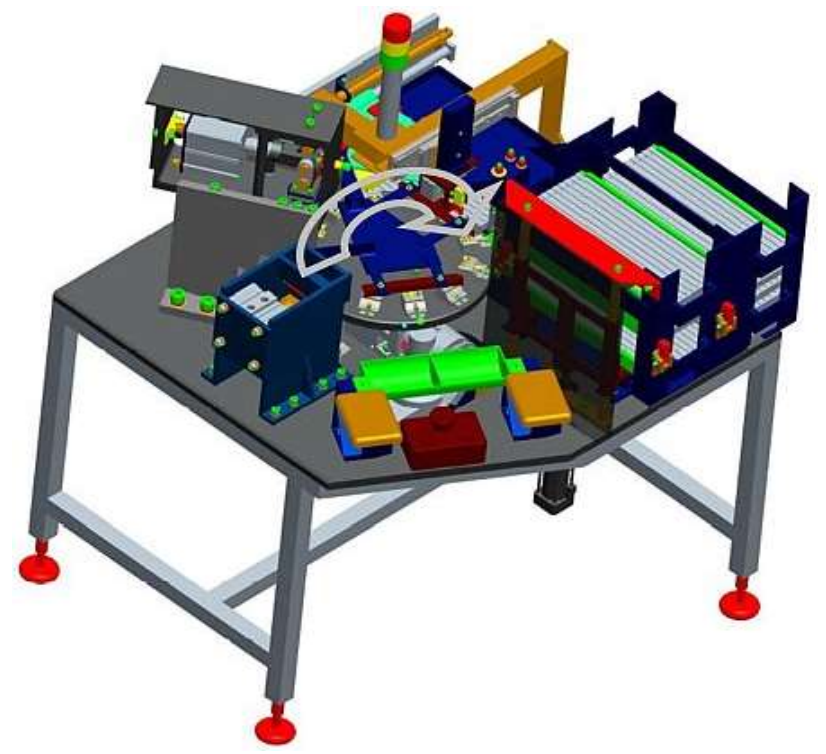

Figure 2: View of the whole

For the production, this would mean:

- Manually fit the resilient slit element onto the respective side pen tip.

- Check the accuracy of prepositioning element placement.

- Pre-positioning the tab on a dedicated device to provide a permanent fixation of the pruning element.

- Check the pre-movement success and check the correct positioning of the fixation elements.

- Fixing yourself mechanically on a dedicated device.

- Checking the accuracy of the operations performed.

- Stack location, palletizing and specified output for further use (for example for circuit breaker assembly line). 
The overall process would be split between more workers, each of whom would perform the designated operation. In this way, work is quicker and more efficient when compared to work when one worker performs all the necessary operations for composition, fixation, and output oriented as required [Kuderjavy 2009], [Daneshjo 2012]. The overall process would be split between more workers, each of whom would perform the designated operation. In this way, work is quicker and more efficient when compared to work when one worker performs all the necessary operations for composition, fixation, and output oriented as required.

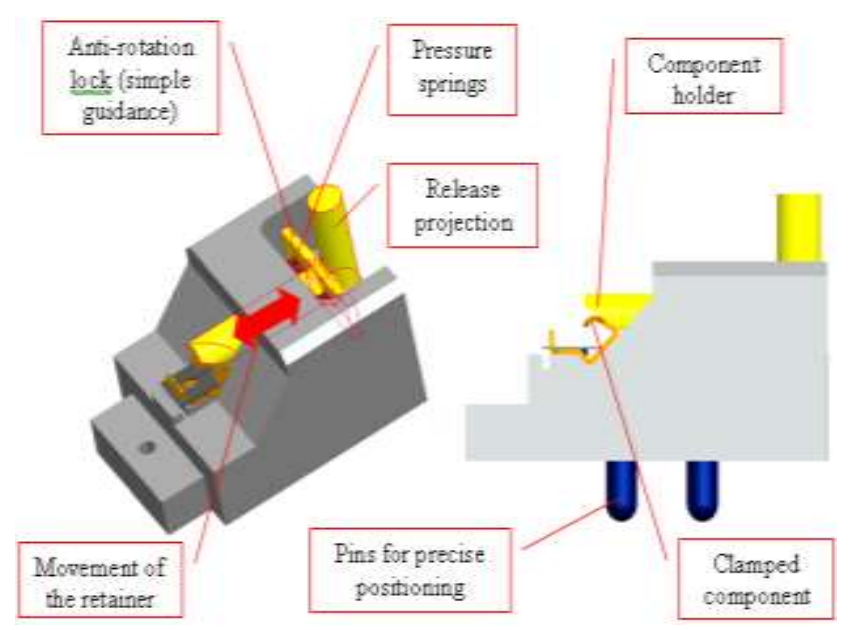

Figure 3: Positioning tool for contact pen

In each work step, there is the check for the presence of individual components due to accidental dropping out of the product - due to the adhesion of the deformed material (" $V$ " projection) to the working tools.

The deformation force on the fixed parts and the tool that acts on it should be perpendicular to the plane (to the "A" area) in which there is a resilient notch element in order to plastically deform the projections "V" (see Fig. 4). Such bent protrusions provide for holding the fixed part and forcing the pressing force with respect to the elastic properties of the notch [Daneshjo 2017], [Fabian 2015].

The deformation force for the fixation operation acts in a direction perpendicular to the plane in which the resilient slit element is located:
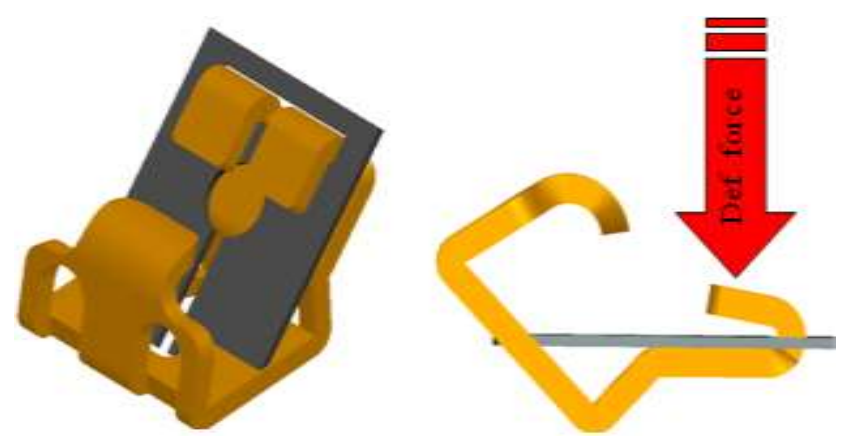

Figure 4: The deformation force for the fixation operation acts in a direction perpendicular to the plane in which the resilient shearing element is located

This operation is carried out by means of a designed singlepurpose pneumatic-mechanical press. This is a module performing the resulting deformation of the contact tab projection, on which a resilient notch element is mounted. A brief mathematical description of the principle is given in kinematics (see Fig. 6). In the solution we combined classical computational methods with solutions using CA systems to show the versatile advantages of using computer technology in designing structures. For this reason, some calculations are also given below [Fabian 2016], [Stanva 2011].

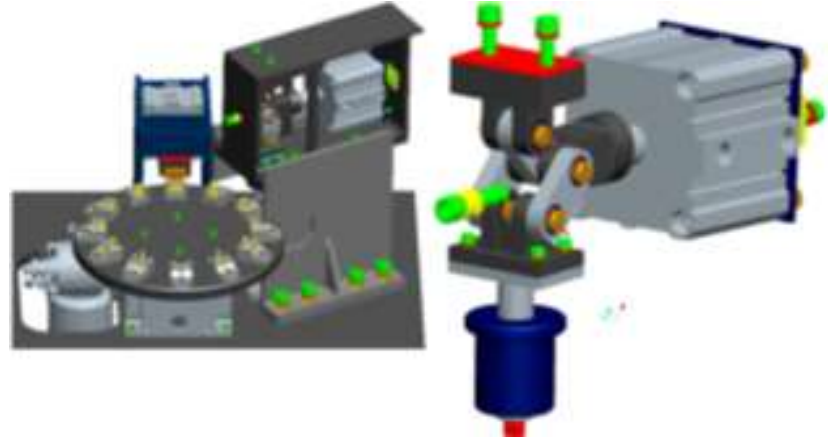

Figure 5: Fixation - View of a dedicated fixation device

\section{CHOICE OF LINEAR PNEUMATIC DRIVE}

As the sliding stroke occurs, there is the displacement of the point "7" to the point "0" along the "K" circle (see Fig. 6). It is necessary to consider the inclination of the actuator in the angle $\beta$. It ensures that optimum operating conditions are maintained so that the forces act only in the axis of the piston rod of this drive, thus avoiding damage to the linear drive.

For the stroke of the pneumatic cylinder (from the triangle of points $3,4,0$ ), the following applies:

$$
H_{1}=|40|=|30| \cdot \sin (\alpha)=R \cdot \sin (\alpha)=40 \cdot \sin \left(41,41^{\circ}\right)=26,5[\mathrm{~mm}]
$$

Where the absolute values of the respective numbers represent the lengths given by the individual numbers according to Fig. 6 .

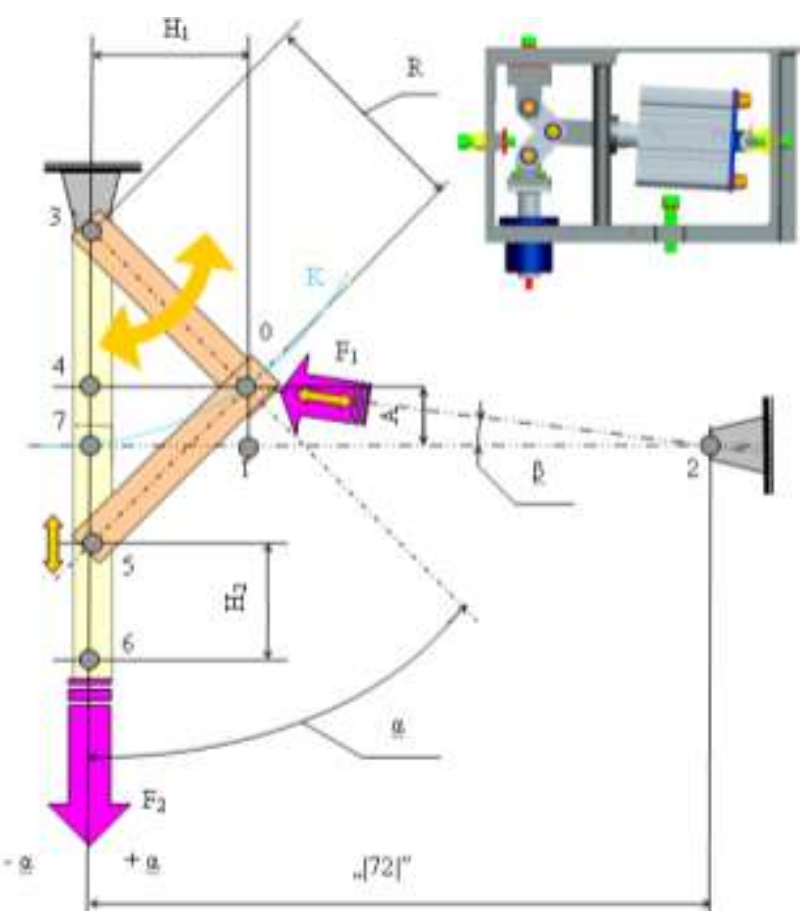

Figure 6: Kinematics solution for the construction of the fixing device

In this case it is possible to neglect the influence of the inclination of this drive (both on the longitudinal and the force values) caused by the movement of the point " 0 " (the pin in the arms of the fixing device) on the part of the circle "K" with the radius "R" 3 ". Therefore, we can assume that the smoothness of the piston is as large as the distance $\mathrm{H} 1$. 
Thus, the selected pneumatic linear drive will be (with consideration for future modifications and neglect of small values) with a $40 \mathrm{~mm}$ extension, namely the CDQ2B100-40D type from the manufacturer SMC (ring mill magnet).

\section{DEPTH OF THE LINEAR PNEUMATIC DRIVE AXIS}

From the mechanical construction and sketch in Fig. 7, it is stated that the distance $|72|$ is the distance corresponding to the position of the extended thrust (i.e. reaching the lower dead end) and applies $|72|=258 \mathrm{~mm}$. Then, in the position where the tool is in the upper dead centre and the angle $\alpha=$ $41.41^{\circ}$, the distance $|12|=|72|-\mathrm{H} 1=258-26.5=231.5 \mathrm{~mm}$. It is evident from Fig. 3 and the triangle of the designated points $0,1,2$

$$
\frac{|01|}{|12|}=\tan (\beta)=\frac{A}{231,5}
$$

And from that:

$$
\beta=\arctan \left(\frac{A}{231,5}\right)=\arctan \left(\frac{\frac{1}{2} H_{2}}{231,5}\right)=\arctan \left(\frac{\frac{1}{2} 20}{231,5}\right)=2,47^{\circ}
$$

Because of the length of distances $|02|$ and $|12|$ is a difference of less than $0.5 \mathrm{~mm}$, it is possible to consider $|02|=|12|$. The following figures show the end state of the proposed singlepurpose press. It is possible to see the end states of the movements of the mechanism, mentioned deflection of the pneumatic drive, and the upper and lower dead ends are obvious. Using motion simulation, it is possible to move the evolved unit to better analyse its activity. During the depiction phase, some deficiencies can be detected, and the system can be fine-tuned by structural modifications and improvements.

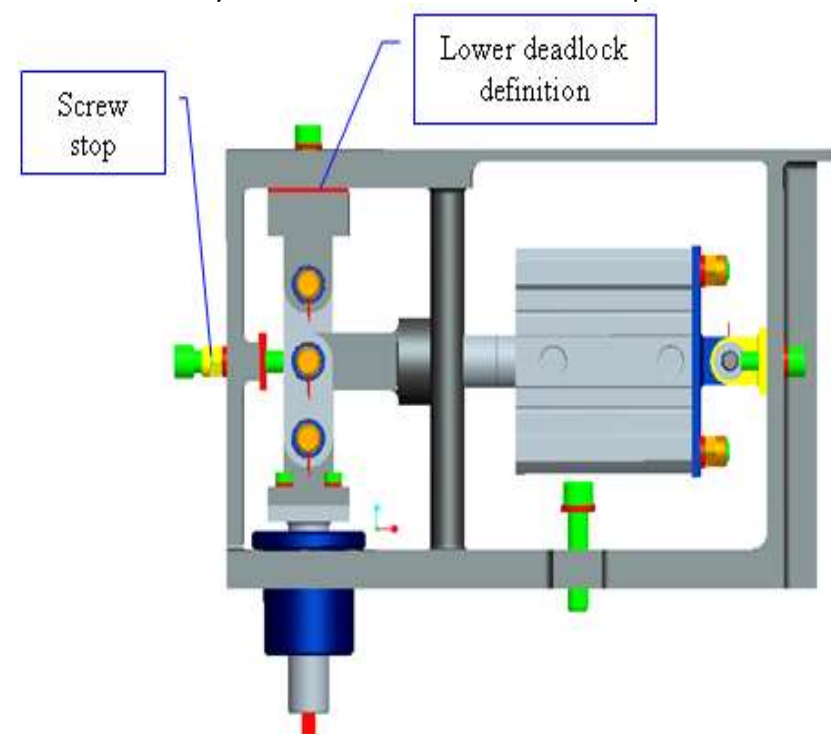

Figure 7: Fixing module - lower damping

The relationship between the deformation force (i.e. the output force) and the input force (force of the pneumatic drive) in relation to the angle of deflection of the arms is described below. Practical utilization of the increase in the output force F2 from the reduction of the angle $\alpha$ is in the plastic deformation of the material of the projection " $V$ " in order to loosen the tension so that the protrusion does not nearly erase at all. Thus ensuring sufficient strain stress on the resilient notch element. Entering boundary conditions - end positions of the fuser of the fuser module is needed to analyse forces. It's a fact, that:

$\frac{F_{1}}{F_{2}}=\tan (\alpha)$

And from that:

$$
F_{2}=F_{1} \cdot \frac{1}{\tan (\alpha)}
$$

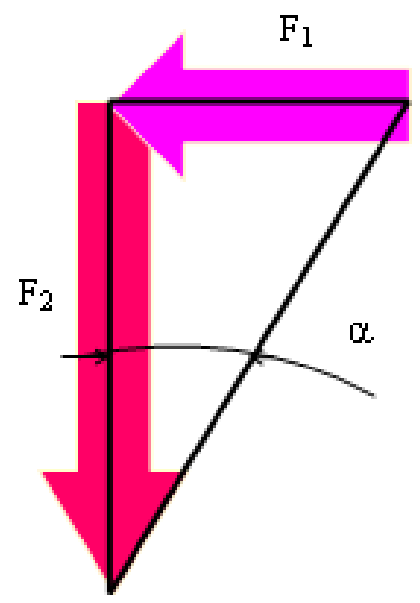

Figure 8: Fixation - transformation force

Where F1 is the force induced by the pneumatic cylinder and the force $\mathrm{F} 2$ is the strain force at the exit of the transformation mechanism of the fixing module $[7,8]$. Angle $\alpha$ is the angle of deflection of the arms in this part of the device, depending on the position of the piston of the pneumatic cylinder, $\alpha$ being the maximum considered angle of deflection of the arms of the fixing device from the vertical position, as previously stated, $\alpha=$ $41,41^{\circ}$. For the working height $\mathrm{H} 2 \mathrm{z}=2.5 \mathrm{~mm}$ (which is the height of the " $V$ " not yet protruding), the angle of the engagement will be, and it will be appreciated that the maximum resistance force of the deformed material will be in the range of $14.36^{\circ}$ to $0^{\circ}$ (corresponding position in the lower deadlock) and the corresponding sections where the tool deforms the material (see Fig. 9).

$\alpha_{Z}=\arccos \left[1-\frac{H_{2 z}}{2 . R}\right]=\arccos \left[1-\frac{2,5}{2.40}\right]=14,36^{\circ}$ 


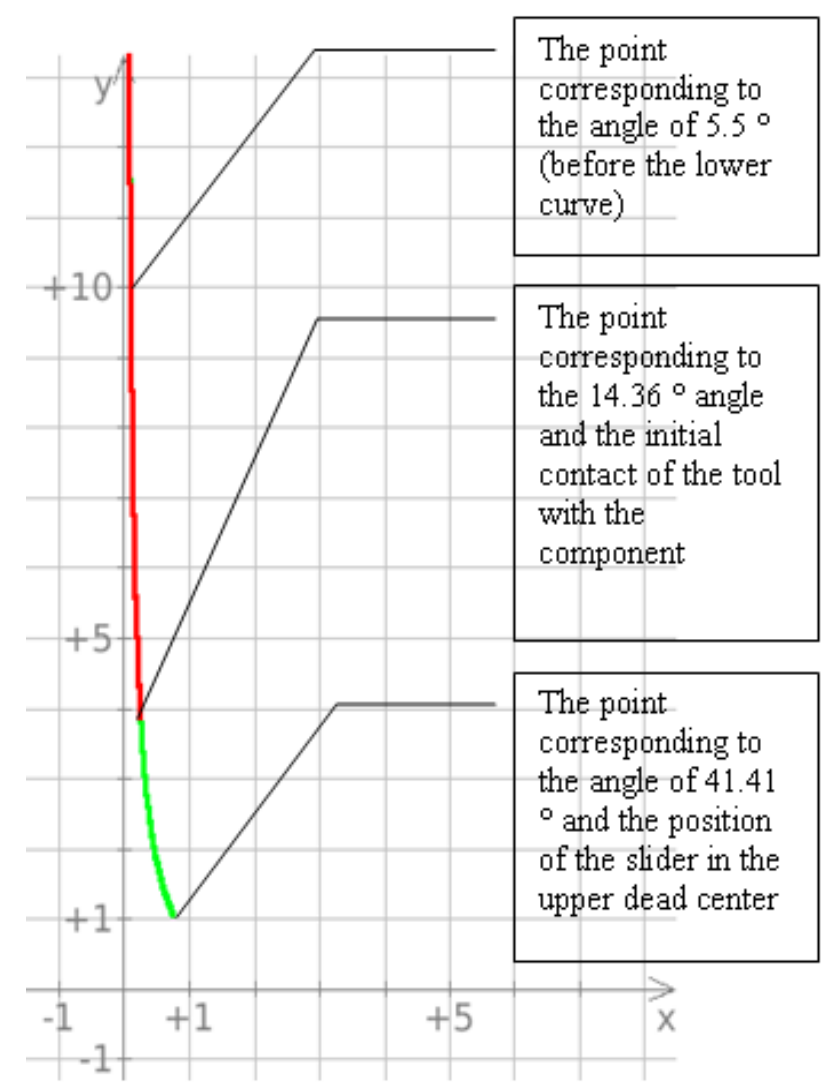

Figure 9: Fixation - Representation of the transformed deformation force, The diagram is a label $x=\alpha[\mathrm{rad}]$ a $y=F_{2} / F_{1}$.

In any construction, it is also necessary to consider inaccuracies in production. Fastening is an operation that requires the most precision, as this module exerts a very large deformation force and the wrong tool end position (the deformation area acting on the component) can damage the entire device [Kuderjavy 2009], [Novak-Marcincin 2014].

The whole module is designed to be as simple as possible, taking into account the correction of inaccuracies in each direction in the range of approximately $5 \mathrm{~mm}$, which is sufficient for the accuracy of the device as a whole.

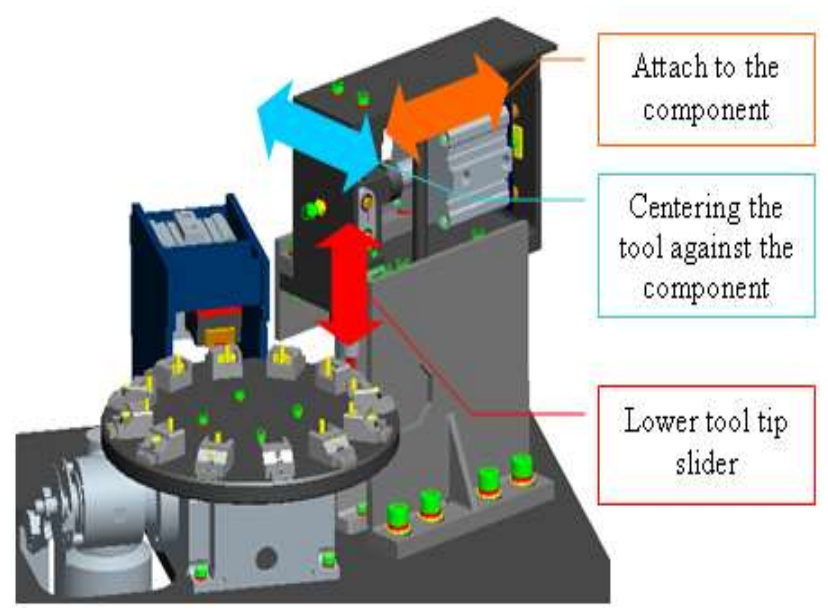

Figure 10: Editing the position of the deforming tool

\section{CONCLUSIONS}

In any construction, it is also necessary to consider inaccuracies in production. Fastening is an operation that requires the most precision, because this module exerts a very high deformation force and the whole tool can be damaged by ensuring the wrong tool end (the deformation area acting on the component).

The entire module is designed to be as simple as possible, taking into account the correction of inaccuracies in each of the directions in the range of approximately $5 \mathrm{~mm}$, which is sufficient for the accuracy of the device as a whole.

By using computer technology and CAD systems, work efficiency increases. The designer will help to analyse the concept of the machine in its design phase, not only in terms of mechanical collisions, but also deformations, in our case bent and fixed components.

The workable solution of the best one will be suggested as a final mechanical problem resolution with detailed description of construction description, component selection and skeleton program design to build a special purpose machinery. Choice is dependent on the selection criteria such as long-term company's practice knowledge, previous experience, technical skills, technical facility and availability some mechanical units in company storage. The designed machine has to be able to be adapted to system expansion in a very short time in the future.

\section{Acknowledgements}

This work has been supported by the Scientific Grant Agency of the Ministry of Education of the Slovak Republic (Project VEGA 1/0251/17)

\section{REFERENCES}

[Daneshjo 2012] Daneshjo Naqib, Computers Modeling and Simulation. In: Advanced Materials Research Vols. 463-464 (2012) pp 1102-1105. ISSN- 1662-8985 Trans Tech Publications, Switzerland.doi:10.4028 AMR.463-464.1102

[Daneshjo 2013] Daneshjo Naqib, Korba Peter, Vargova Renata and Tahzib Baryalai, Application of 3D Modeling and Simulation Using Modular Components. In: Applied Mechanics and Materials, ISSN: 1660-9336 Vol. 389, pp 957-962, Online available since (C)(2013), Trans Tech Publications Switzerland :10.4028 /www.scientific.net/AMM.389.957.

[Daneshjo 2017] Daneshjo Naqib, Majernik Milan, Krivosudska Jana and Danishjoo Enayat. Modelling Technical and Economic Parameters in Selection of Manufacturing Devices. In: TEM Journal. Volume 6, No 4, Pages 738-744, ISSN 2217-8309, ISSN 2217-8333, DOI:10.18421/TEM64-13,. Published by: UIKTEN Association for Information Communication Technology Education and Science. Novi Pazar, Serbia. http://www.temjournal.com/

[Fabian 2015] Fabian Michal, Boslai Robert, Izol Peter, Janekova Jaroslava, Fabianova Jana, Fedorko Gabriel and Bozek Pavol, Use of Parametric 3D Modelling - Tying Parameter Values to Spreadsheets at Designing Molds for Plastic Injection. 2015. In: Manufacturing Technology. Vol. 15, no. 1 (2015), p. 24-31. ISSN 1213-2489

[Fabian 2016] Fabian Michal, Stanova Eva, Fedorko Gabriel, Kmet Stanislav, Fabianova Jana and Krajnak Jozef, Parametric CAD model of a double-lay six strand wire rope.. In: Manufacturing Technology. Vol. 16, no. 3, p. 489-496. - ISSN 1213-2489

[Kuderjavy 2010] Kuderjavy Peter, Daneshjo Naqib and Fabian, Michal, Single-purpose automated devices for the manufacture of components of electrical connectors. In: Ai Magazine: automotive industry magazine. Roč. 3, č. 3, s. 74-77. - ISSN 1337-7612 
[Kuderjavy 2009] Kuderjavy Peter, Design of construction and specification of operation of a modular automated system for the assembly of contacts to switches. 1 elektronický optický disk (CD-ROM). In: Novus Scientia 2009: 11. National conference of doctoral students of the Faculty of Mechanical Engineering of Technical Universities: ISBN 978-80-553-0305-5 [Novak-Marcincin 2014] Novak-Marcincin, Jozef, Torok Jozef, Novakova-Marcincinová Ludmila, Barna Jozef and Janak Miroslav, Use of alternative scanning devices for creation of 3D models of machine parts. In: Tehnički vjesnik - Technical Gazette. Vol. 21, no. 1 (2014), p. 177-181. - ISSN 1330-3651

[Stanva 2011] Stanova Eva, Fedorko Gabriel, Fabian Michal and Kmet Stanislav, Computer modelling of wire strands and ropes Part 1 Theory and computer implementation. In: Advances in Engineering Software. Vol. 42, no. 6, p. 305-315. - ISSN 09659978

[Stejskal 2017] Stejskal Tomas, Kral Jan ml., Rudy Vladimir, Melko Jaroslav, Rjabusin Adrian and Pavlikova Ludmila, Impact of the technological conditions of plane surface machining on a triangular milling cutter on the residual hysteresis of the movement axis of the machine. In: Advances in Science and Technology Research Journal. Vol. 11, no. 3, p. 240-245. - ISSN 2299-8624

\section{CONTACTS}

Assoc. prof. Naqib Daneshjo, PhD.

University of Economics in Bratislava, Faculty of Business Economics with seat in Kosice

Department of Commercial Business

Tajovskeho 13, 04130 Kosice, Slovak republic

tel.: 0042155722 3248, daneshjo47@gmail.com

www.euke.sk
Assoc. prof. RNDr Zuzana Hajduova, PhD.

University of Economics in Bratislava, Faculty of Business Economics with seat in Kosice

Department of Commercial Business

Tajovskeho 13, 04130 Kosice, Slovak republic

tel.: 0042155722 3212, zuzana.hajduova@euke.sk,

www.euke.sk

\section{Ing. Erika Dudas-Pajerska, PhD.}

University of Economics in Bratislava, Faculty of Business Economics with seat in Kosice

Department of Commercial Business

Tajovskeho 13, 04130 Kosice, Slovak republic

tel.: 0042155722 3248, daneshjo47@gmail.com

www.euke.sk

Ing. Enayat Danishjoo, PhD.

Thk rhythm automotive GMBH

Fichtenstraße 37, 40233 Düsseldorf, Germany

tel.: 0049162 8547669, danishjoo@web.de, 